\title{
Progesterone-based compounds affect immune responses and susceptibility to infections at diverse mucosal sites
}

\author{
Olivia J Hall ${ }^{1}$ and Sabra L Klein ${ }^{1}$
}

Over 100 million women worldwide are currently on progesterone-based contraceptives to improve their health outcomes through reduced maternal mortality and family planning. In addition to their role in reproduction, progesterone-based compounds modulate immune responses throughout the body, particularly at mucosal sites. By binding to receptors located in immune cells, including natural killer cells, macrophages, dendritic cells, and T cells, as well in non-immune cells, such as epithelial and endothelial cells, progesterone-based compounds alter cellular signaling and activity to affect the outcome of infections at diverse mucosal sites, including the genital, gastrointestinal, and respiratory tracts. As the use of progesterone-based compounds, in the form of contraceptives and hormone-based therapies, continue to increase worldwide, greater consideration should be given to how the immunomodulatory effects these compounds alter the outcome of diseases at mucosal sites beyond the reproductive tract, which has profound implications for women's health.

\section{INTRODUCTION}

Females and males experience changes in the hormonal milieu throughout the life course, which are typically not considered in the context of infectious diseases at mucosal sites. Prior to puberty, circulating concentrations of estrogens and progesterone (P4) in females and androgens in males are low, with concentrations increasing significantly after puberty and through adulthood, with fluctuations in females occurring during the menstrual cycle and to a greater extend during pregnancy (see Figure 1). ${ }^{1}$ With older age, concentrations of estrogens and progestins decline rapidly in females and concentrations of androgens decline gradually in males. Only recently, have we begun to appreciate that these changes in sex steroids over the life course impact immune responses ${ }^{2}$ and the outcome of infectious diseases within but also outside of the reproductive tract. ${ }^{3}$ Mucosal sites, including the genital, respiratory, and gastrointestinal tracts, are particularly vulnerable to infections as they come in contact with the exterior of the body and form the main route of entry for infections. ${ }^{4}$ Despite these mucosal sites being anatomically distinct compartments, immune responses and the impact of sex steroids, in particular
P4 and related compounds, can be similar and suggest that that P4 can affect the outcome infectious diseases beyond the reproductive tract.

\section{Progestins and receptor signaling}

Natural P4 is produced by the corpus luteum during the menstrual cycle in non-pregnant females and its production is sustained at high levels by the placenta during pregnancy. Serum levels of P4 fluctuate during the menstrual cycle with a peak of $20 \mathrm{ng} \mathrm{ml}^{-1}$ during the luteal phase and the nadir $\left(<1 \mathrm{ng} \mathrm{ml}^{-1}\right)$ during the follicular phase ${ }^{5}$ (Figure 1). During pregnancy, the production of $\mathrm{P} 4$ is maintained by the placenta with increases from 12 to $90 \mathrm{ng} \mathrm{ml}^{-1}$ during first trimester and up to $300 \mathrm{ng} \mathrm{ml}^{-1}$ during the third trimester of pregnancy ${ }^{5}$ (Figure 1). Synthetic analogs of P4, termed progestins, are used as hormonal contraceptives by over 20 million young adult women in the United States alone. ${ }^{6}$

Progestins and P4 can freely diffuse through the cell membrane and signal through the progesterone receptor (PR), located in the cytoplasm, which when bound, translocates to the nucleus, and binds progesterone response elements to

${ }^{1}$ W. Harry Feinstone Department of Molecular Microbiology and Immunology, The Johns Hopkins Bloomberg School of Public Health, Baltimore, Maryland USA. Correspondence: SL Klein (sklein2@jhu.edu) 


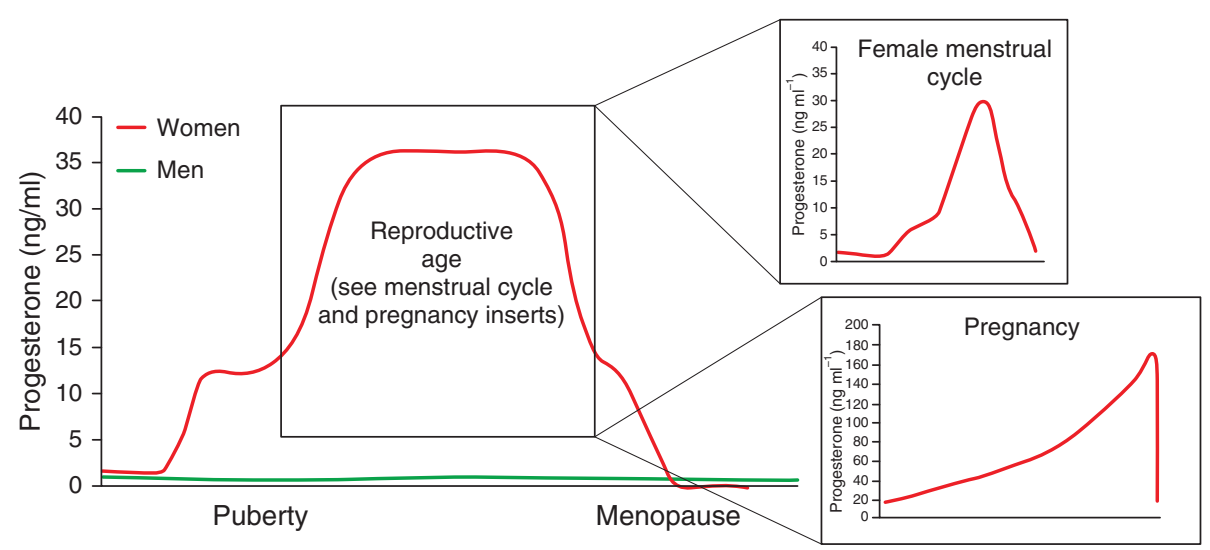

Figure 1 Serum progesterone concentrations vary between men and women and over the life course. Concentrations of progesterone fluctuate over the life course in females, with increased concentrations at puberty, cyclical changes during the menstrual cycle, and a steady rise during pregnancy followed by a sharp decline post-partum. At menopause, concentrations steadily decline to levels that are similar to those prior to puberty. In men, levels of progesterone remain steady throughout the life course. Based on values from. ${ }^{1}$

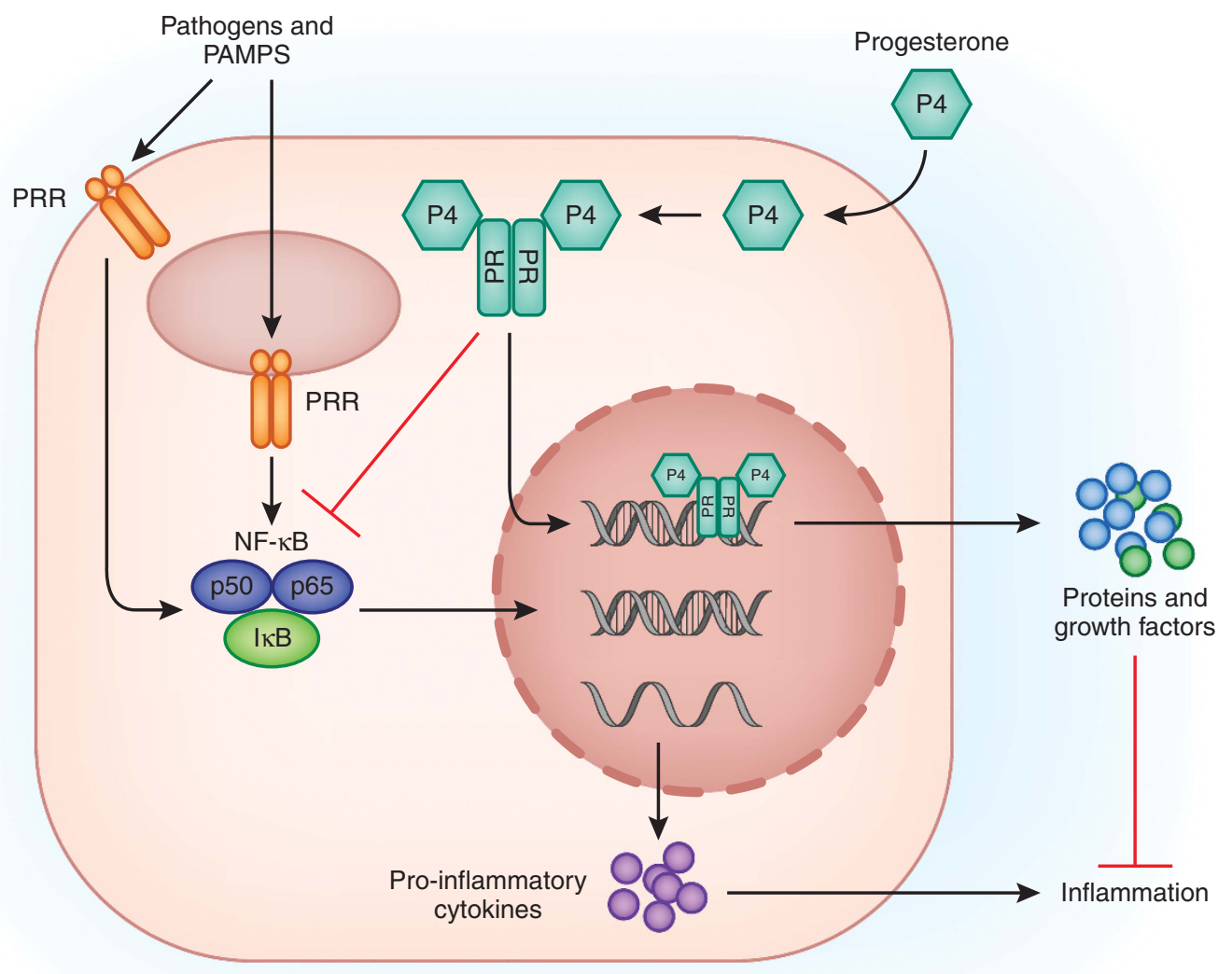

Figure 2 Progesterone receptor signaling in immune cells. Pathogens and pathogen associated molecular patterns (PAMPs) are sensed through pattern recognition receptors (PRRs) either on the surface of cells or intracellularly. PPRs signal through the NF- $\kappa B$ pathway to induce the production of pro-inflammatory cytokines and inflammation. Progesterone (P4), being lipophilic, diffuses across the lipid bilayer of the cell membrane, binds to the progesterone receptor (PR) in the cytosol, and the complex dimerizes and translocates to the nucleus of the cell to alter cellular transcription. This interaction can directly interfere with the NF- $\mathrm{kB}$ pathway to lower inflammatory responses. Progesterone when bound to its receptor can also induce the transcription of proteins and growth factors that dampen inflammation and promote repair.

alter transcription and downstream signaling (Figure 2). PR signaling can also occur in a non-genomic signaling manner via the MAPK or PI3K/Akt pathway, for example, or through membrane-bound PRs that signal by either increasing cAMP or through the JNK pathway and bypass the classical PR pathway all together. ${ }^{7-10}$ PRs have two isoforms, $\mathrm{A}$ and $\mathrm{B}$, which are 
derived from the same gene. ${ }^{11}$ Progestins bind the PR with higher affinity than P4; with levonorgestrel (LNG), for example, binding the PR with a $300 \%$ affinity relative to $\mathrm{P} 4{ }^{12}$ These PR are present in a wide range of tissues, in a variety of different cell types, including immune cells such as natural killer (NK) cells, macrophages, dendritic cells (DCs), T cells and non-immune cells, such as epithelial cells, endothelial cells, and neuronal cells. ${ }^{13-15}$ Natural and synthetic forms of $\mathrm{P} 4$ can also signal through other steroid receptors including the androgen, glucocorticoid, and mineralocorticoid receptors. ${ }^{16,17}$ For example, depot medroxyprogestone acetate (DMPA) signals through both the PR and glucocorticoid receptor, LNG signals only through the PR, and $\mathrm{P} 4$ signals preferentially though the PR but can also signal through the glucocorticoid receptor. ${ }^{12}$ As each of these receptors are widely distributed throughout the body, the effects of natural and synthetic forms of P4 are not limited to the reproductive tract, but can occur at other mucosal sites, including the respiratory and gastrointestinal tracts.

Bringing together diverse bodies of literature, we seek to illustrate that progestins affect immune responses to microbes at diverse mucosal sites. Because women are exposed to both natural and synthetic forms of $\mathrm{P} 4$ throughout their lifetime, we will use this hormone to make the broader point that the hormonal milieu can drastically alter the outcome of infectious diseases at mucosal sites. Whether the immunomodulatory effects of P4-based compounds confer protection or increase susceptibility to infectious diseases can be cell- and site-specific, which will be addressed. Although pregnancy and the associated hormonal changes, including the rise in P4, can have profound effects on immune responses and the outcome of infectious diseases at diverse sites, this goes beyond the goals of this review and are discussed in detail elsewhere. ${ }^{18}$

Progesterone-based contraceptives. The "pill" which was approved by the Food and Drug Agency in 1960 is typically composed of a combination of progestins (Table 1) and estrogen, but many hormonal contraceptives, such as intrauterine devices, contain progestin only formulations. ${ }^{19}$ Progestins exert their reproductive effects by thickening the mucus, suppressing ovulation by altering the luteinizing hormone and follicle stimulating hormone surges, and making the endometrium inhospitable for implantation. ${ }^{20}$ Many different contraceptive formulations exist, with new generations of progestins being developed that have higher affinity to the PR thereby reducing the dose required to be efficacious as well as reducing potential side-effects. Progestins can be used in conjunction with estrogen in combined oral contraceptives, or alone in the form of implants, injections (usually with DMPA), intrauterine devices, rings, or as an emergency contraceptive (Table 1) ${ }^{17}$ In the United States alone, $35 \%$ of adult women are currently using hormonal methods of contraception, and $88 \%$ of all adult women in the United States have been exposed to progestins in some form of contraceptives. ${ }^{21}$ Male hormonal contraception is currently being evaluated, with administration of either LNG or etonorgestrel reducing pituitary luteinizing hormone and follicle stimulating hormone production, testicular testosterone production, and spermatogenesis without affecting secondary sexual characteristics. ${ }^{22}$

Progesterone-based therapies. In addition to their use in birth control, $\mathrm{P} 4$ and progestins are also used in combination with estrogen in hormone replacement therapy in perimenopausal women to prevent the proliferative effects of estrogen on endometrial cells, which can lead to cancer and increased bone density. ${ }^{23}$ The potential side-effects of progestin-containing hormone replacement therapy, including increased breast cancer risks and heart disease, raised concerns following the Women's Health Initiative trial, but the study was conducted with medroxyprogesterone acetate (MPA), which can transactivate the androgen and glucocorticoid receptor and thus lead to increased undesired side-effects. ${ }^{24}$ Newer generations of progestins are now used to prevent these side-effects and reduce the risk of breast cancer. ${ }^{25}$

Progesterone-based oral contraceptives also have been used for their "off-label" beneficial effects on conditions such as acne, polycystic ovary syndrome, and dysmenorrhea. Progestins can increase bone density and prevent osteoporosis. ${ }^{26,27}$ More recently, $\mathrm{P} 4$ was shown to have a neuroprotective role following injury in the central nervous system by dampening inflammation and promoting repair of myelin fibers in the context of traumatic brain injury and multiple sclerosis. ${ }^{28,29}$ As such, $\mathrm{P} 4$ is currently being used in clinical trials for treatment of traumatic brain injury and strokes in both men and women. ${ }^{29-31}$

\section{Effects of progestins on immune responses}

The presence of PRs on a wide variety of immune cells, suggests that these cells can respond to P4-based treatments (Figure 2). In vitro studies demonstrate that exposure of cells to P4 alters the immune environment in various tissues and cell culture systems by promoting an anti-inflammatory state (Table 2). Progesterone generally inhibits inflammatory innate immune responses. In vitro studies show that $\mathrm{P} 4$ can suppress activation of macrophages and DCs. ${ }^{32,33}$ When $\mathrm{P} 4$ is bound to its receptor, it directly interferes with the transcription factor NF- $\kappa B$ through transrepression and inhibits gene transcription downstream of the NF- $\mathrm{BB}$ pathway, including cyclooxygenase-2 to decrease inflammation ${ }^{32,34-36}$ (Figure 2). In human primary myometrial cells, P4 inhibits the MAPK pathway and downstream cyclooxygenase- 2 and IL-1 $\beta$ expression via the glucocorticoid receptor. ${ }^{37}$ Progesterone can also decrease inflammation by inhibiting the production of proinflammatory cytokines (e.g., TNF- $\alpha$, IFN- $\gamma$, and IL-12) and increasing production of anti-inflammatory cytokines, including IL-10. ${ }^{33,38-40}$ Progestin treatment of endometrial stem cell cultures, isolated from female patients with endometriosis reduces the expression of Il6, Mcpl, and Tnf $\alpha$ mRNA. ${ }^{41}$ In addition, exposure of endometrial stem cell cultures to either TNF- $\alpha$ or IL-1 $\beta$ decreases intracellular expression of PRs. ${ }^{38} \mathrm{Not}$ all studies demonstrate anti-inflammatory effects of progestins. For example, concentrations of MIP-1, IL-6, and IL-8 in 
Table 1 List of commonly used progestins

\begin{tabular}{lll}
\hline Progestin & Uses (reproductive system) & Brand name $^{\mathrm{a}}$ \\
\hline Progesterone (P4) & POC, HRT, dysmenorrhea treatment, ART & Prometrium \\
Norethindrone & COC, POC, endometriosis treatment, dysmenorrhea treatment & Micronor, Camila \\
Depot medroxyprogesterone acetate (DMPA) & Injectable contraceptive, HRT & Depo-Provera \\
Levonorgestrel (LNG) & COC, IUD, emergency contraception, implants & Mirena, Plan B \\
Etonogestrel & Vaginal ring, implants & NuvaRing, Implanon \\
Drospirenone & COC, HRT & Yasmin \\
\hline
\end{tabular}

Abbreviations: ART, assisted reproductive technology; COC, combined oral contraceptives; HRT, hormonal replacement therapy; IUD, intrauterine device; POC, P4 only contraceptive.

arand names may differ depending on the country.

Table 2 The effects of progestins on immune responses

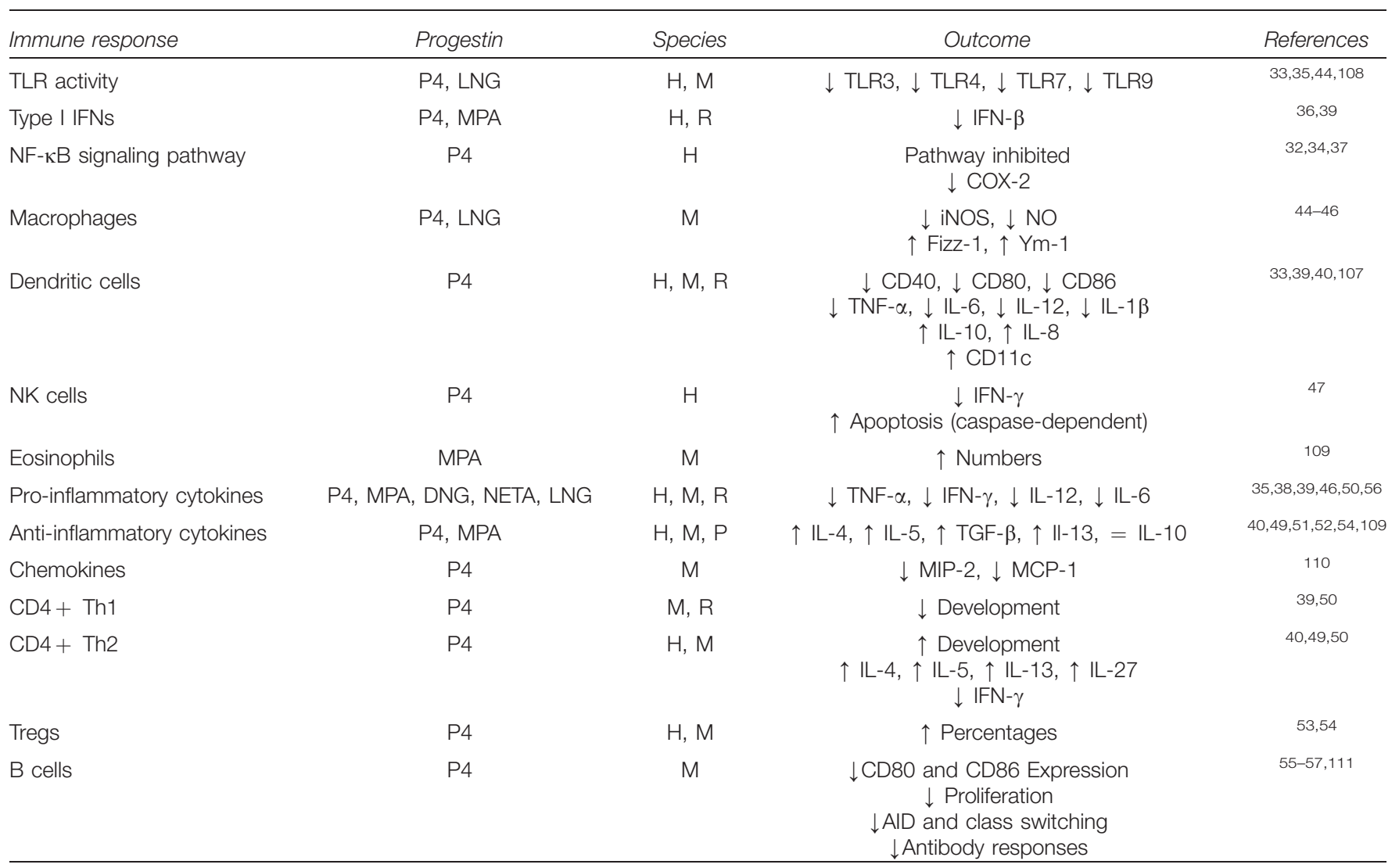

Abbreviations: AID, activation-induced cytidine deaminase; COX-2, cyclooxygenase 2; DNG, dienogest; H, human; iNOS, inducible nitric oxide synthase; M, mouse; MPA, medroxyprogesterone acetate; NETA, noresthisterone acetate; NO, nitric oxide; $P$, primate; P4, progesterone; R, rat; TLR, toll-like receptor.

endocervical swabs collected from women taking DMPA are increased, ${ }^{42,43}$ which may be mediated by signaling through the glucocorticoid receptor rather than the PR in the genital tract (Table 2).

In rodent bone-marrow derived DCs (BMDCs), in vitro administration of either P4 or LNG downregulates the activation of the toll-like receptors (TLR) 3 and 4 and the production of IL- 6 , IL-12p 40 , TNF- $\alpha$, and IL- $1 \beta$ as well as the expression of CD80 and CD86 following stimulation with TLR ligands. ${ }^{33,39}$ When BMDCs are co-cultured with $\mathrm{T}$ cells, the presence of $\mathrm{P} 4$ reduces $\mathrm{T}$-cell proliferation in response to lipopolysaccharide (LPS). ${ }^{39}$ Similarly, P4 treatment of the macrophage cell line RAW264.7 inhibits TLR3, TLR4, and TLR9 signaling in response to Poly I:C, LPS, or CpG DNA, respectively, and downstream IL-6 and nitric oxide production. ${ }^{35,44}$ In vitro treatment with $\mathrm{P} 4$ alters the phenotype of murine macrophages by inducing the expression of Fizz-1 and YM-1, two markers of alternatively activated macrophages, and decreasing the production of nitric oxide following LPS stimulation. ${ }^{45}$ In murine bone marrow-derived macrophages treated with LPS, P4 but not LNG decreases nitric oxide production and the ability to lyse Leishmania intracellular 
parasites. ${ }^{46}$ Natural killer cells isolated from human peripheral blood mononuclear cells (PBMCs) are susceptible to P4-induced cell death, which can be blocked by treatment with the P4 antagonist, RU-486. ${ }^{47}$ Eosinophil numbers in ovariectomized rats treated with $\mathrm{P} 4$ are increased as compared with ovariectomized rats treated with placebo. ${ }^{48}$

Progesterone also alters the distribution and activity of $\mathrm{T}$ cells. Treatment of either murine or human $\mathrm{T}$ cells in vitro with $\mathrm{P} 4$ can skew naive $\mathrm{T}$ cells away from Th1 responses and toward a Th2 type response, with increased production of IL-4, IL-5, and IL-10. ${ }^{40,49,50}$ In human monocyte-derived DCs, treatment with $\mathrm{P} 4$ induces a Th2 environment with increased concentrations of IL-10, IL-13, and IL-27. ${ }^{40}$ In T-cell lines, the addition of $\mathrm{P} 4$ to the culture media induces a Th2 environment, with greater secretion of IL- 4 and IL- 5 as compared with nonP4-treated cultures. ${ }^{49}$ Murine T cells cultured to differentiate into either Th1 or Th 2 cells in the presence of $\mathrm{P} 4$, show a strong bias toward Th2 with decreased IFN- $\gamma$ production and enhanced production of IL-4. ${ }^{50}$ In vivo, the presence of P4 induces the production of TGF- $\beta$ in the endometrium. ${ }^{51,52}$ During pregnancy, high levels of $\mathrm{P} 4$ can shift the immune response towards a CD $4+$ Treg (T regulatory) phenotype. ${ }^{53}$ In human cord blood cells, $\mathrm{P} 4$ induces the differentiation of Tregs and suppresses Th17 cells through the modulation of transcriptions factors, such as STAT5 and STAT3. ${ }^{54}$

In B cells, the effects of P4 treatment are less well characterized. In vitro studies with B cells and endometrial cell co-cultures from mice show that in the presence of $\mathrm{P} 4, \mathrm{~B}$ cells have reduced expression of CD80 and CD86 and a limited ability to present antigen. ${ }^{55} \mathrm{~B}$-cell hybridomas treated with $\mathrm{P} 4$ show lower cellular proliferation and antibody production. ${ }^{56} \mathrm{In}$ murine splenic B cells, P4 treatment decreases activationinduced deaminase mRNA and the ability of these cells to undergo somatic hypermutation and class-switch recombination. ${ }^{57}$ Acute administration of $\mathrm{P} 4$ in combination with low dose estradiol to female mice significantly reduces B lymphopoiesis, suggesting that these hormones are negative regulators of B-cell development in bone marrow. ${ }^{58}$ During pulmonary infection, females treated with time-release capsules of either P4 and LNG exhibit lower antibody production systemically in serum and locally in brochoalveolar lavage fluid, than do nonhormone treated female mice. ${ }^{59}$ Taken together, these data illustrate that $\mathrm{P} 4$ and related compounds alter the functioning of immune cells, which could have profound effects on the pathogenesis of diseases at mucosal sites.

\section{THE EFFECTS OF PROGESTINS ON DISEASES AT MUCOSAL SITES \\ Infections of the genital tract}

Epidemiological studies show that when compared with males, females have higher rates of sexually transmitted infections (STIs), including human immunodeficiency virus (HIV), herpes simplex virus (HSV), gonorrhea, and chlamydia. The different stages of the menstrual cycle along with the use of hormonal contraceptives have been shown in both human and animal models to increase susceptibility to STIs, ${ }^{60}$ with progestins implicated as a factor that contributes to this heightened susceptibility ${ }^{61-64}$ (Table 3). Many reasons have been proposed for the detrimental effects of progestins on STIs including altered thickness of the vaginal epithelium, ${ }^{65,66}$ increased expression of virus entry co-receptors, ${ }^{67-69}$ and induction of an anti-inflammatory cytokine milieu lacking essential anti-microbial, pro-inflammatory cytokines, such as IFN- $\gamma$ and TNF- $\alpha .{ }^{64,68}$ In some cases, these effects can be species-specific. For example, although progestins thin the vaginal epithelium in non-human primates, ${ }^{66}$ they can cause a thickening of the vaginal epithelium in humans. ${ }^{65}$

HIV. The effects of progestins have been extensively studied in the context of HIV, where multiple epidemiological studies, in vivo studies in non-human primates, and in vitro studies have assessed the effects of progestins on the outcome of HIV acquisition, transmission, and virus replication. In both humans and non-human primates, the risk of HIV acquisition is increased in females during the luteal phase of the menstrual cycle, when P4 is at its highest levels, and following use of hormonal contraceptives containing progestins. ${ }^{70-75}$ In nonhuman primates, there is an increased risk of simian immunodeficiency virus and higher viral loads during the luteal phase of the menstrual cycle ${ }^{76}$ and following P4 treatment. ${ }^{64,77}$ In macaques treated with DMPA, acute viremia and transmission of multiple viral variants is increased concomitantly with a decrease in virus-specific IFN- $\gamma$ production. ${ }^{64}$ In women taking DMPA, levels of the chemokine CCL5 are significantly increased in cervical swabs, but concentrations of pro-inflammatory cytokines such as IL- $1 \beta$ or IL- 6 remain similar to those in women not taking contraceptives. ${ }^{43}$ In vitro data show that treatment of human PBMCs with P4 leads to increased expression of the HIV receptor CXCR4 but not CCR5 in both HIV infected and non-infected women. ${ }^{69}$ Conversely, in endometrial biopsies from HIV-negative females, LNG reduced the expression of CCR5 on both $\mathrm{CD} 4+$ and CD8 $+\mathrm{T}$ cells. ${ }^{78}$ Genital epithelial cells also have a higher uptake of HIV by endocytosis when exposed to $\mathrm{P} 4$ and to a greater extent with MPA. ${ }^{79}$ Although controversial, these data suggest that progestins alter the risk of HIV infection by modulating the expression of chemokine receptors used for virus entry.

In addition to affecting the expression of chemokine receptors, progestins alter the cytokine responses of immune cells during HIV infection. In human PBMCs, upon activation with cytokine-coated activating beads, PBMCs treated with MPA have reduced IFN- $\gamma$, IL-6, IL-12, IL-17, and TNF- $\alpha$ production, and both MPA and P4 reduce IL-2 and IL-4 production. ${ }^{68}$ When these PBMCs were infected with HIV, MPA but not P4 increased viral titers. ${ }^{68}$ In addition, cervicolavage fluid from women taking DMPA has lower concentrations of IFN- $\alpha$ as compared with concentrations in women not taking any form of contraceptive. ${ }^{68}$ Conversely, higher concentrations of $\mathrm{P} 4$ in women are associated with increased production of type I IFNs by plasmacytoid DCs following stimulation with HIV encoded TLR7 ligands. ${ }^{80}$ 


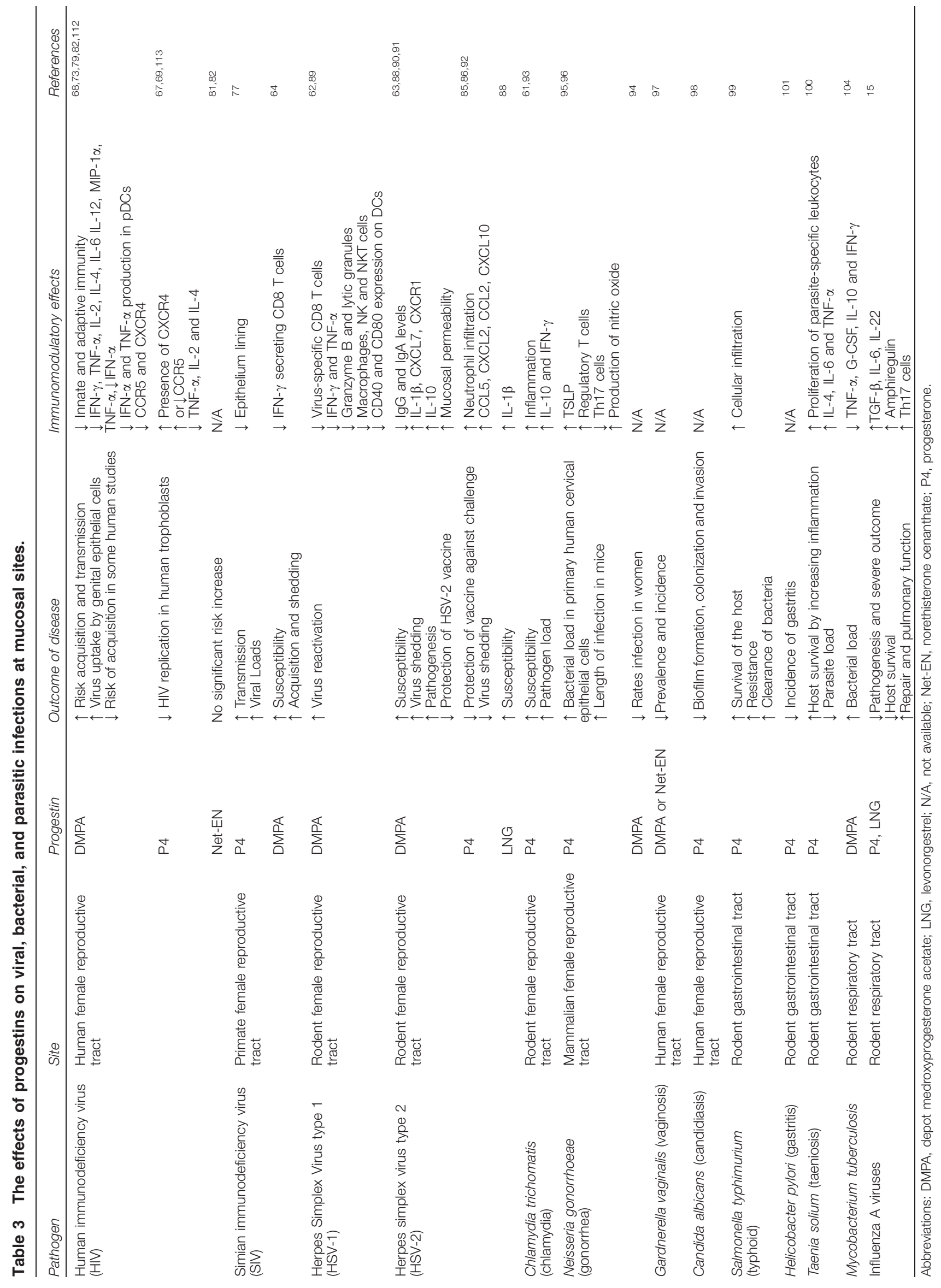


In conclusion, many of the epidemiological studies of progestins and HIV focus on women using DMPA, which may increase the risk of HIV acquisition; whereas neither Net-EN nor LNG increase the risk of HIV acquisition. ${ }^{73,81-}$ 83 DMPA may promote HIV acquisition by modulating immune responses through glucocorticoid receptor signaling, whereas LNG reduces HIV acquisition through PR signaling.

HSV. Progestins can increase susceptibility to HSV and decrease protection during HSV vaccination in humans and mice. ${ }^{62,63,84-88}$ Studies in ovariectomized mice show that DMPA leads to HSV-1 reactivation, with reduced numbers, lytic activity, and cytokine production (e.g., IFN- $\gamma$ and TNF- $\alpha$ ) in virus-specific CD8 + T cells. ${ }^{62}$ DMPA impairs the CD8 + $\mathrm{T}$-cell response by decreasing the expression of co-stimulatory molecules on DCs. ${ }^{89}$ In the genital mucosa of mice, treatment with DMPA, P4, or LNG increases susceptibility to HSV-2 by stimulating the production of IL- $1 \beta$, mucosal permeability, and entry of inflammatory cells through reduced expression of cadherin desmoglein-1a. ${ }^{88,90,91}$ Human primary genital epithelial cells are highly susceptible to HSV-2 infection, but unlike murine models, $\mathrm{P} 4$ treatment is protective and limits HSV-2 shedding as compared with control-treated cultures. ${ }^{92}$ In the context of HSV-2 vaccination in mouse models, both DMPA and $\mathrm{P} 4$ reduce anti-HSV-2 IgG and IgA in vaginal washes, increase viral shedding, and fail to protect mice following HSV 2 challenge as compared with estradiol-treated mice. ${ }^{85,90,91}$ Taken together, progestins increase susceptibility to HSV at population and organismal levels of analysis, but the precise cell types mediating these effects remain elusive.

Other STIs. In rats, $\mathrm{P} 4$ increases susceptibility to the bacterium Chlamydia trichomatis by increasing inflammatory responses, as measured by MHC class II expression in uterine epithelial cells, production of IFN- $\gamma$ and IL-10, and pathogen load. ${ }^{61,93}$ In women using DMPA, susceptibility to infection with Neisseria gonorrhea is significantly decreased, ${ }^{94}$ but treatment of primary human cervical cells with P4 increases bacterial survival within human cervical epithelial cells, which is associated with increased AKT activity and inducible nitric oxide synthase production. ${ }^{95}$ When P4-treated female mice are infected with N. gonorrhea, bacterial loads and the duration of infection increase, which are associated with greater levels of thymic stromal lymphopoietin and Tregs and lower Th17 cell responses. ${ }^{96}$ Vaginosis can be caused by many pathogens, the most common being Candida albicans; $\mathrm{P} 4$ and progestinbased hormonal contraceptives have all been shown to be beneficial by reducing prevalence and incidence of vaginitis. ${ }^{97}$ In vitro studies show that $\mathrm{P} 4$ can decrease $C$. albicans biofilm formation thus preventing colonization and invasion of the vaginal mucosa. ${ }^{98}$ Taken together these data show that the antiinflammatory properties of progestins may lead to increased susceptibility to STIs, yet the type of progestin may affect the risk of acquisition or disease progression differentially in part through differences in hormone receptor signaling pathways.

\section{Infections of the gastrointestinal tract}

A limited number of studies have examined the role of P4-based compounds in the gastrointestinal tract, with focus on either bacteria or parasitic infections (Table 3). In the context of murine infection with Salmonella typhimurium, the causative agent of typhoid, P4 treatment increases host survival by increasing the infiltration of peritoneal cells and promoting clearance of the bacteria. ${ }^{99}$ Similarly, following infection of hamsters with the parasite, Taenia solium, P4 increases host survival and decreases tapeworm length by recruiting mast cells and increasing levels of the pro-inflammatory IL-4, IL-6, and TNF- $\alpha$ in the intestinal mucosa which can promote parasite elimination. ${ }^{100}$ In the context of gastritis due to Helicobacter pylori infections, $\mathrm{P} 4$ reduces gastrointestinal inflammation in ovariectomized gerbils and reduces the effects of gastritis. ${ }^{101} \mathrm{In}$ addition to pathogenic bacteria, commensal bacteria in the gastrointestinal tract are responsive to and can even alter concentrations of sex steroids. ${ }^{102,103}$ For example, adoptive transfer of gut commensals from male to female mice increases concentrations of androgens in females and alters the pathogenesis of autoimmune diseases. ${ }^{102,103}$ Whether P4-based compounds, including the use of contraceptives alter the composition of the microbiome requires consideration. Based on available data, it can be concluded that progestins protect against gastrointestinal infections by increasing host survival through their immunomodulatory effects.

\section{Infections of the respiratory tract}

To date, few studies have assessed the role of P4-based compounds on infectious diseases in the respiratory tract (Table 3). DMPA alters the outcome of Mycobacterium tuberculosis infection in mice by inducing an antiinflammatory environment, including reduced production of TNF- $\alpha$, IFN- $\gamma$, and G-CSF, which contributes greater bacterial burden. ${ }^{104}$ In mice infected with influenza A virus, treatment with either P4 or LNG prevents severe outcome by decreasing pulmonary inflammation and promoting faster recovery during a primary infection. ${ }^{15,59}$ P4-based treatments promote pulmonary repair following clearance of influenza A viruses by elevating levels of TGF- $\beta$, IL-6, IL-22, and increasing numbers of regulatory CD39+ Th17 cells in the lungs. Production of the epidermal growth factor amphiregulin is also increased following P4 treatment, which promotes proliferation and repair of respiratory epithelial cells during influenza A virus infection ${ }^{15}$ (Figure 3). Treatment with either P4 or LNG also reduces virus-specific antibody titers as well as virus-specific memory $\mathrm{CD} 8+\mathrm{T}$ cells numbers, which results in worse outcome following secondary influenza A virus challenge in female mice. ${ }^{59}$ Although the anti-inflammatory effects of P4-based compounds protect against a primary virus infection, the reduction in memory $\mathrm{T}$-cell responses increase susceptibility to secondary influenza A virus challenge. Because P4-based compounds reduce inflammation and expedite repair of lung tissue following primary influenza A virus infection, females may be less susceptible to secondary bacterial 


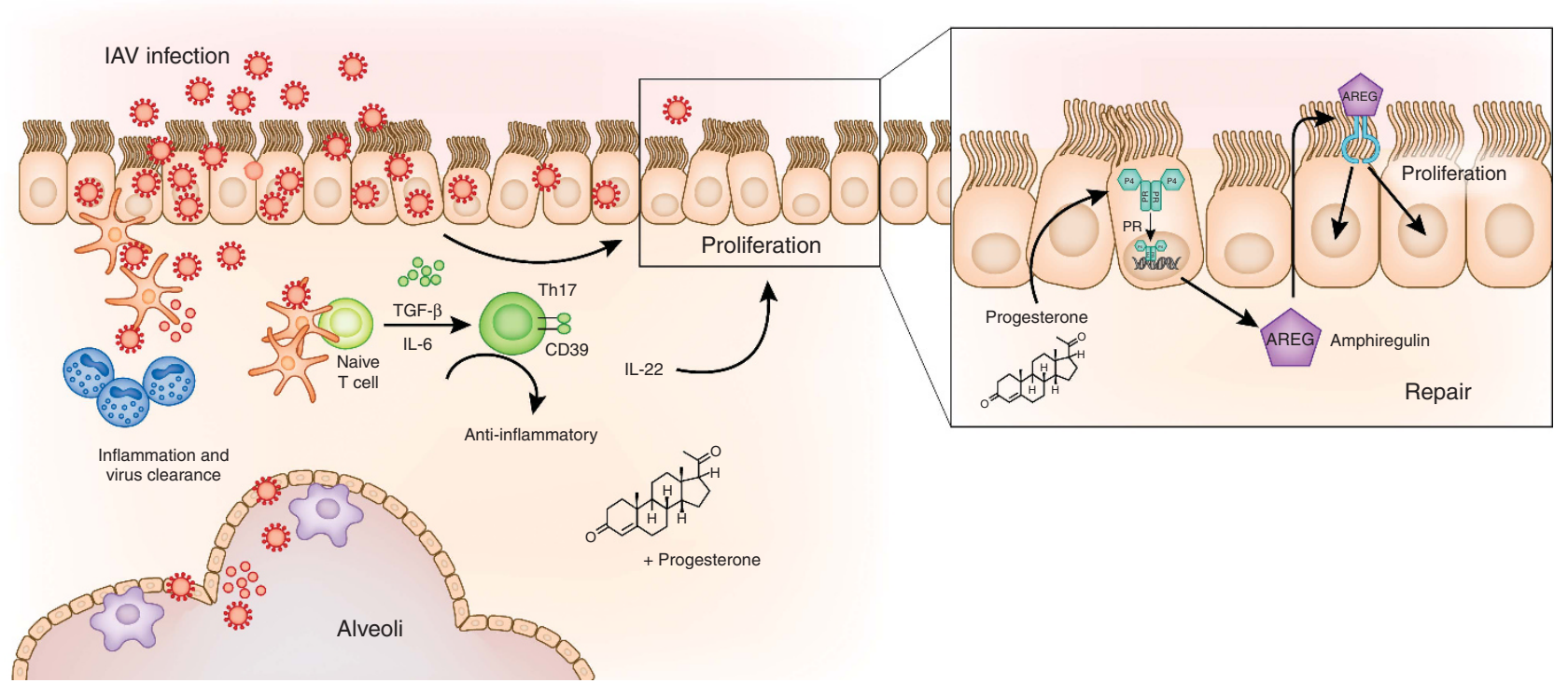

Figure 3 Progesterone (P4) reduces inflammation and promotes repair of the respiratory epithelium to protect against influenza A virus (IAV) infection. Influenza A viruses (IAV) infect airway epithelial cells which can produce pro-inflammatory cytokines and activate immune cells, such as alveolar macrophages (brown cells), DCs (blue cells), and neutrophils (purple cells), to cause inflammation and, along with CD8 + T cells (not depicted), lead to virus clearance. In the presence of P4, pulmonary production of IL-6 and TGF- $\beta$ and recruitment of regulatory CD39+ Th17 cells (green cells) is increased and creates an anti-inflammatory milieu. Th17 cells can also produce IL-22, which like TGF- $\beta$, promotes proliferation of epithelial cells (orange cells) and repair of the damaged epithelium. Amphiregulin (AREG) is a growth factor that is induced by P4 signaling through the progesterone receptor (PR). AREG signals through the epidermal growth factor receptor (EGFR) to induce the proliferation of epithelial cells, which leads to repair of the damaged epithelium.

infections, which are the primary cause of mortality following influenza A virus infection in humans.

\section{CONCLUSIONS AND FUTURE DIRECTIONS}

The use of P4-based compounds is growing and despite strong evidence for a role in modulating immune responses, their effects outside of reproductive health are rarely considered. Not only have hormonal contraceptives been used by over $88 \%$ of adult women in the United States, ${ }^{21}$ but they are further recommended for use in situations where there are extreme concerns about congenital infection, such as during the current Zika virus epidemic in the Americas. ${ }^{105}$

The impact of progestins on infectious disease outcome depends on the type of immune response induced to control the infection and repair damaged tissue. For example, during influenza A virus infection of the respiratory tract, excessive inflammation and tissue damage lead to severe symptoms, whereas the presence of $\mathrm{P} 4$ or LNG dampens inflammation and leads to faster recovery. ${ }^{15,59}$ Conversely, during HSV-1 infection of the reproductive tract, dampened inflammation, including reduced numbers CD8 $+\mathrm{T}$ cells and lower secretion of pro-inflammatory cytokines, caused by DMPA leads to increased virus reactivation. ${ }^{62,89}$ Similarly, following infection of the reproductive tract with Neisseria gonorrhoeae, treatment with progestins decreases the number of Th17 cells and prevents proper control of the bacterial infection. ${ }^{95,96,106}$ As illustrated in these examples, progestins alter the number and function of multiple immune cell types, which likely contributes to differences in the impact of progestins on the outcome of infections at diverse mucosal sites.

One common observation across diverse infections at mucosal sites is that treatment with progestins leads to reduced inflammation. In antigen-presenting cells, such as DCs, progestins inhibit activation and inflammatory pathways. ${ }^{33,39,40,107}$ In T cells, progestins promote anti-inflammatory phenotypes ${ }^{40,49,50,53,54}$ and in epithelial cells ${ }^{14,15}$ at mucosal sites, progestins promote repair and proliferation. We interpret these observations to illustrate the importance of progestins in mucosal immunity. Future studies must evaluate the mechanistic effects of progestins on receptor signaling pathways in diverse cell types, including immune cells, epithelial cells, and endothelial cells, at mucosal sites. We must also systematically evaluate the possible therapeutic as well as the detrimental effects of progestin-based compounds in the context of infectious as well as non-infectious diseases at mucosal sites. In summary, the data reviewed provide significant evidence that P4 and related compounds have profound effects on mucosal immunity and the pathogenesis of diverse diseases in females.

\section{ACKNOWLEDGMENTS}

We thank Drs Andrew Pekosz, Nicola Heller, and Wayne Mitzner for feedback on earlier drafts of this manuscript.

\section{AUTHOR CONTRIBUTIONS}

O.J.H. and S.L.K. conceived the idea and drafted the outline, O.J.H. and S.L.K wrote the manuscript, S.L.K. edited the manuscript, O.J.H. drafted the figures and tables. 


\section{DISCLOSURE}

The authors declared no conflict of interest.

c 2017 Society for Mucosal Immunology

\section{REFERENCES}

1. Jameson, J.L. Endocrinology: Adult and pediatric, 7th edn. (Elsevier Sauders, Philadelphia, PA, 2006.

2. Fink, A.L. \& Klein, S.L. Sex and gender impact immune responses to vaccines among the elderly. Physiology (Bethesda) 30, 408-416 (2015).

3. Klein, S.L. \& Flanagan, K.L. Sex differences in immune responses. Nat. Rev. Immunol. 16, 626-638 (2016).

4. McGhee, J.R. \& Fujihashi, K. Inside the mucosal immune system. PLoS Biol. 10, e1001397 (2012).

5. Speroff, F.A. Clinical Gynecologic Endocrinology and Infertility, 8th edn. (Wolters Kluwers Lippincott Williams and Wilkins, Philadelphia, 2011).

6. Petitti, D.B. Clinical practice. Combination estrogen-progestin oral contraceptives. N. Engl. J. Med. 349, 1443-1450 (2003).

7. Rajaram, R.D. \& Brisken, C. Paracrine signaling by progesterone. Mol. Cell. Endocrinol. 357, 80-90 (2012).

8. Moussatche, P. \& Lyons, T.J. Non-genomic progesterone signalling and its non-canonical receptor. Biochem. Soc. Trans. 40, 200-204 (2012).

9. Kaore, S.N., Langade, D.K., Yadav, V.K., Sharma, P., Thawani, V.R. \& Sharma, R. Novel actions of progesterone: what we know today and what will be the scenario in the future? J. Pharm Pharmacol. 64, 1040-1062 (2012).

10. Dressing, G.E., Goldberg, J.E., Charles, N.J., Schwertfeger, K.L. \& Lange, C.A. Membrane progesterone receptor expression in mammalian tissues: a review of regulation and physiological implications. Steroids 76 , 11-17 (2011).

11. Horwitz, K.B. \& Alexander, P.S. In situ photolinked nuclear progesterone receptors of human breast cancer cells: subunit molecular weights after transformation and translocation. Endocrinology 113, 2195-2201 (1983).

12. Sitruk-Ware, R. New progestagens for contraceptive use. Hum ReprodUpdate 12, 169-178 (2006).

13. Teilmann, S.C., Clement, C.A., Thorup, J., Byskov, A.G. \& Christensen, S.T. Expression and localization of the progesterone receptor in mouse and human reproductive organs. J. Endocrinol. 191, 525-535 (2006).

14. Jain, R., Ray, J.M., Pan, J.H. \& Brody, S.L. Sex hormone-dependent regulation of cilia beat frequency in airway epithelium. Am. J. Respir. Cell Mol. Biol. 46, 446-453 (2012).

15. Hall, O.J. et al. Progesterone-based therapy protects against influenza by promoting lung repair and recovery in females. PLOS Pathog. 12, e1005840 (2016).

16. Griekspoor, A., Zwart, W., Neefjes, J. \& Michalides, R. Visualizing the action of steroid hormone receptors in living cells. Nucl. Recept. Signal $\mathbf{5}$, e003 (2007).

17. Christin-Maitre, S. History of oral contraceptive drugs and their use worldwide. Best Pract. Res. Clin. Endocrinol. Metab. 27, 3-12 (2013).

18. Robinson, D.P. \& Klein, S.L. Pregnancy and pregnancy-associated hormones alter immune responses and disease pathogenesis. Horm. Behav. 62, 263-271 (2012).

19. Colton, F.B. Steroids and "the pill": early steroid research at Searle. Steroids 57, 624-630 (1992).

20. Evans, G. \& Sutton, E.L. Oral contraception. Med. Clin. North Am. 99, 479-503 (2015).

21. Daniels, K., Daugherty, J. \& Jones, J. Current contraceptive status among women aged 15-44: United States, 2011-2013. NCHS Data Brief 173, 1-8 (2014).

22. Chao, J.H. \& Page, S.T. The current state of male hormonal contraception. Pharmacol. Ther. 163, 109-117 (2016).

23. Sturdee, D.W. Are progestins really necessary as part of a combined HRT regimen?. Climacteric 16, 79-84 (2013).

24. Sitruk-Ware, R. \& El-Etr, M. Progesterone and related progestins: potential new health benefits. Climacteric 16, 69-78 (2013).

25. Schindler, A.E. The "newer" progestogens and postmenopausal hormone therapy (HRT). J. Steroid Biochem. Mol. Biol. 142, 48-51 (2014).

26. Christiansen, C. Prevention and treatment of osteoporosis: a review of current modalities. Bone 13, S35-S39 (1992).
27. Viola, A.S., Castro, S., Marchi, N.M., Bahamondes, M.V., Viola, C.F. \& Bahamondes, L. Long-term assessment of forearm bone mineral density in postmenopausal former users of depot medroxyprogesterone acetate. Contraception 84, 122-127 (2011).

28. Schumacher, M., Hussain, R., Gago, N., Oudinet, J.P., Mattern, C. \& Ghoumari, A.M. Progesterone synthesis in the nervous system: implications for myelination and myelin repair. Front. Neurosci. 6, 10 (2012).

29. Stein, D.G. \& Wright, D.W. Progesterone in the clinical treatment of acute traumatic brain injury. Expert Opin. Investig. Drugs 19, 847-857 (2010).

30. Wright, D.W. et al. ProTECT: a randomized clinical trial of progesterone for acute traumatic brain injury. Ann. Emerg. Med. 49, 402 e391-392 (2007).

31. Skolnick, B.E. et al. A clinical trial of progesterone for severe traumatic brain injury. N. Engl. J. Med. 371, 2467-2476 (2014).

32. Hardy, D.B., Janowski, B.A., Corey, D.R. \& Mendelson, C.R. Progesterone receptor plays a major antiinflammatory role in human myometrial cells by antagonism of nuclear factor-kappaB activation of cyclooxygenase 2 expression. Mol. Endocrinol. 20, 2724-2733 (2006).

33. Jones, L.A., Kreem, S., Shweash, M., Paul, A., Alexander, J. \& Roberts, C.W. Differential modulation of TLR3- and TLR4-mediated dendritic cell maturation and function by progesterone. J. Immunol. 185, 4525-4534 (2010).

34. Kalkhoven, E., Wissink, S., van der Saag, P.T. \& van der Burg, B. Negative interaction between the RelA(p65) subunit of NF-kappaB and the progesterone receptor. J. Biol. Chem. 271, 6217-6224 (1996).

35. Su, L., Sun, Y., Ma, F., Lu, P., Huang, H. \& Zhou, J. Progesterone inhibits Toll-like receptor 4-mediated innate immune response in macrophages by suppressing NF-kappaB activation and enhancing SOCS1 expression. Immunol. Lett. 125, 151-155 (2009).

36. Lei, K. \& Chen, L. et al. Progesterone acts via the nuclear glucocorticoid receptor to suppress IL-1 beta-induced COX-2 expression in human term myometrial cells. PLOS ONE 7, e50167 (2012).

37. Lei, K. et al. Progesterone and the repression of myometrial inflammation: the roles of MKP-1 and the AP-1 system. Mol. Endocrinol. 29, 1454-1467 (2015).

38. Grandi, G. et al. Progestin suppressed inflammation and cell viability of tumor necrosis factor-alpha-stimulated endometriotic stromal cells. Am. J. Reprod. Immunol. 76, 292-298 (2016).

39. Butts, C.L. et al. Progesterone inhibits mature rat dendritic cells in a receptor-mediated fashion. Int. Immunol. 19, 287-296 (2007).

40. Kyurkchiev, D., Ivanova-Todorova, E., Hayrabedyan, S., Altankova, I. \& Kyurkchiev, S. Female sex steroid hormones modify some regulatory properties of monocyte-derived dendritic cells. Am. J. Reprod. Immunol. 58, 425-433 (2007).

41. Grandi, G. et al. Inflammation influences steroid hormone receptors targeted by progestins in endometrial stromal cells from women with endometriosis. J. Reprod. Immunol. 117, 30-38 (2016).

42. Deese, J. et al. injectable progestin-only contraception is associated with increased levels of pro-inflammatory cytokines in the female genital tract. Am. J. Reprod. Immunol. 74, 357-367 (2015).

43. Fichorova, R.N. et al. The contribution of cervicovaginal infections to the immunomodulatory effects of hormonal contraception. MBio 6, e00221-00215 (2015).

44. Pisetsky, D.S. \& Spencer, D.M. Effects of progesterone and estradiol sex hormones on the release of microparticles by RAW 264.7 macrophages stimulated by Poly(l:C). Clin. Vacc. Immunol. 18, 1420-1426 (2011).

45. Menzies, F.M., Henriquez, F.L., Alexander, J. \& Roberts, C.W. Selective inhibition and augmentation of alternative macrophage activation by progesterone. Immunology 134, 281-291 (2011).

46. Jones, L.A. et al. Toll-like receptor-4-mediated macrophage activation is differentially regulated by progesterone via the glucocorticoid and progesterone receptors. Immunology 125, 59-69 (2008).

47. Arruvito, L. et al. NK cells expressing a progesterone receptor are susceptible to progesterone-induced apoptosis. J Immunol 180 , 5746-5753 (2008).

48. Grunert, G., Porcia, M., Neumann, G., Sepulveda, S. \& Tchernitchin, A.N. Progesterone interaction with eosinophils and with responses already induced by oestrogen in the uterus. J Endocrinol 102, 295-303 (1984). 
49. Piccinni, M.P. et al. Progesterone favors the development of human T helper cells producing Th2-type cytokines and promotes both IL-4 production and membrane CD30 expression in established Th1 cell clones. J Immunol 155, 128-133 (1995).

50. Miyaura, H. \& Iwata, M. Direct and indirect inhibition of Th1 development by progesterone and glucocorticoids. J Immunol 168, 1087-1094 (2002).

51. Kim, M.R. et al. Progesterone-dependent release of transforming growth factor-beta1 from epithelial cells enhances the endometrial decidualization by turning on the Smad signalling in stromal cells. Mol. Hum. Reprod. 11, 801-808 (2005).

52. Rodriguez, G.C. et al. Progestin treatment induces apoptosis and modulates transforming growth factor-beta in the uterine endometrium. Cancer Epidemiol. Biomarkers Prev. 17, 578-584 (2008).

53. Mao, G. et al. Progesterone increases systemic and local uterine proportions of CD4 + CD25 + Treg cells during midterm pregnancy in mice. Endocrinology 151, 5477-5488 (2010).

54. Lee, J.H., Ulrich, B., Cho, J., Park, J. \& Kim, C.H. Progesterone promotes differentiation of human cord blood fetal T cells into T regulatory cells but suppresses their differentiation into Th17 cells. J. Immunol. 187, 1778-1787 (2011).

55. Zhang, L., Chang, K.K., Li, M.Q., Li, D.J. \& Yao, X.Y. Mouse endometrial stromal cells and progesterone inhibit the activation and regulate the differentiation and antibody secretion of mouse B cells. Int. J. Clin. Exp. Pathol 7, 123-133 (2014).

56. Canellada, A., Blois, S., Gentile, T. \& Margni Idehu, R.A. In vitro modulation of protective antibody responses by estrogen, progesterone and interleukin-6. Am. J. Reprod. Immunol. 48, 334-343 (2002).

57. Pauklin, S. \& Petersen-Mahrt, S.K. Progesterone inhibits activation-induced deaminase by binding to the promoter. J. Immunol. 183, 1238-1244 (2009).

58. Medina, K.L. \& Kincade, P.W. Pregnancy-related steroids are potential negative regulators of $\mathrm{B}$ lymphopoiesis. Proc. Natl. Acad. Sci. USA 91, 5382-5386 (1994).

59. Hall, O.J. et al. Progesterone-based contraceptives reduce adaptive immune responses and protection against heterosubtypic infection with influenza A viruses. J. Virol. 91, e02160-16 (2017).

60. Wira, C.R., Rodriguez-Garcia, M. \& Patel, M.V. The role of sex hormones in immune protection of the female reproductive tract. Nat. Rev. Immunol. 15, 217-230 (2015).

61. Kaushic, C., Murdin, A.D., Underdown, B.J. \& Wira, C.R. Chlamydia trachomatis infection in the female reproductive tract of the rat: influence of progesterone on infectivity and immune response. Infect. Immun. $\mathbf{6 6}$, 893-898 (1998).

62. Cherpes, T.L., Busch, J.L., Sheridan, B.S., Harvey, S.A. \& Hendricks, R.L. Medroxyprogesterone acetate inhibits CD8 + Tcell viral-specific effector function and induces herpes simplex virus type 1 reactivation. J. Immunol. 181, 969-975 (2008).

63. Gillgrass, A.E., Ashkar, A.A., Rosenthal, K.L. \& Kaushic, C. Prolonged exposure to progesterone prevents induction of protective mucosal responses following intravaginal immunization with attenuated herpes simplex virus type 2. J. Virol. 77, 9845-9851 (2003).

64. Trunova, N. et al. Progestin-based contraceptive suppresses cellular immune responses in SHIV-infected rhesus macaques. Virology 352, 169-177 (2006).

65. Ildgruben, A.K., Sjoberg, I.M. \& Hammarstrom, M.L. Influence of hormonal contraceptives on the immune cells and thickness of human vaginal epithelium. Obstet. Gynecol. 102, 571-582 (2003).

66. Hild-Petito, S., Veazey, R.S., Larner, J.M., Reel, J.R. \& Blye, R.P. Effects of two progestin-only contraceptives, Depo-Provera and Norplant-II, on the vaginal epithelium of rhesus monkeys. AIDS Res. Hum. Retroviruses 14, S125-S130 (1998).

67. Sheffield, J.S., Wendel, G.D. Jr., McIntire, D.D. \& Norgard, M.V. The effect of progesterone levels and pregnancy on HIV-1 coreceptor expression. Reprod. Sci. 16, 20-31 (2009).

68. Huijbregts, R.P., Helton, E.S., Michel, K.G., Sabbaj, S., Richter, H.E. \& Goepfert, P.A. et al. Hormonal contraception and HIV-1 infection: medroxyprogesterone acetate suppresses innate and adaptive immune mechanisms. Endocrinology 154, 1282-1295 (2013).
69. Cabrera-Munoz, E., Fuentes-Romero, L.L., Zamora-Chavez, J., Camacho-Arroyo, I. \& Soto-Ramirez, L.E. Effects of progesterone on the content of CCR5 and CXCR4 coreceptors in PBMCs of seropositive and exposed but uninfected Mexican women to HIV-1. J. Steroid Biochem. Mol. Biol. 132, 66-72 (2012).

70. Saba, E. et al. Productive HIV-1 infection of human cervical tissue ex vivo is associated with the secretory phase of the menstrual cycle. Mucosal Immunol. 6, 1081-1090 (2013).

71. Byrne, E.H., Anahtar, M.N., Cohen, K.E., Moodley, A., Padavattan, N. \& Ismail, N. et al. Association between injectable progestin-only contraceptives and HIV acquisition and HIV target cell frequency in the female genital tract in South African women: a prospective cohort study. Lancet Infect. Dis. 16, 441-448 (2016).

72. Heffron, R. et al. Use of hormonal contraceptives and risk of HIV-1 transmission: a prospective cohort study. Lancet Infect. Dis. 12, 19-26 (2012).

73. Morrison, C.S. et al. Hormonal contraception and the risk of HIV acquisition: an individual participant data meta-analysis. PLoS Med. 12, e1001778 (2015).

74. Birse, $K$. et al. Molecular signatures of immune activation and epithelial barrier remodeling are enhanced during the luteal phase of the menstrual cycle: implications for HIV susceptibility. J. Virol. 89, 8793-8805 (2015).

75. Lavreys, L. et al. Injectable contraceptive use and genital ulcer disease during the early phase of HIV-1 infection increase plasma virus load in women. J. Infect. Dis. 189, 303-311 (2004).

76. Vishwanathan, S.A. et al. High susceptibility to repeated, low-dose, vaginal SHIV exposure late in the luteal phase of the menstrual cycle of pigtail macaques. J. Acquir. Immune Defic. Syndr. 57, 261-264 (2011).

77. Marx, P.A. et al. Progesterone implants enhance SIV vaginal transmission and early virus load. Nat. Med. 2, 1084-1089 (1996).

78. Achilles, S.L., Creinin, M.D., Stoner, K.A., Chen, B.A., Meyn, L. \& Hillier, S.L. Changes in genital tract immune cell populations after initiation of intrauterine contraception. Am. J. Obstet. Gynecol. 211, 489 e481-489 e489 (2014).

79. Ferreira, V.H. et al. Medroxyprogesterone acetate regulates HIV-1 uptake and transcytosis but not replication in primary genital epithelial cells, resulting in enhanced T-cell infection. J. Infect. Dis. 211, 1745-1756 (2015).

80. Meier, A. et al. Sex differences in the Toll-like receptor-mediated response of plasmacytoid dendritic cells to HIV-1. Nat. Med. 15, 955-959 (2009).

81. Polis, C.B., Phillips, S.J., Hillier, S.L. \& Achilles, S.L. Levonorgestrel in contraceptives and multipurpose prevention technologies: does this progestin increase HIV risk or interact with antiretrovirals?. AIDS 30, 2571-2576 (2016).

82. Ralph, L.J., McCoy, S.I., Shiu, K. \& Padian, N.S. Hormonal contraceptive use and women's risk of HIV acquisition: a meta-analysis of observational studies. Lancet Infect. Dis. 15, 181-189 (2015).

83. Phillips, S.J., Polis, C.B. \& Curtis, K.M. The safety of hormonal contraceptives for women living with HIV and their sexual partners. Contraception 93, 11-16 (2016).

84. Kaushic, C., Roth, K.L., Anipindi, V. \& Xiu, F. Increased prevalence of sexually transmitted viral infections in women: the role of female sex hormones in regulating susceptibility and immune responses. J. Reprod. Immunol. 88, 204-209 (2011).

85. Bhavanam, S., Snider, D.P. \& Kaushic, C. Intranasal and subcutaneous immunization under the effect of estradiol leads to better protection against genital HSV-2 challenge compared to progesterone. Vaccine $\mathbf{2 6}$, 6165-6172 (2008).

86. Gillgrass, A.E., Tang, V.A., Towarnicki, K.M., Rosenthal, K.L. \& Kaushic, C. Protection against genital herpes infection in mice immunized under different hormonal conditions correlates with induction of vaginaassociated lymphoid tissue. J. Virol. 79, 3117-3126 (2005).

87. Parr, M.B. \& Parr, E.L. Vaginal immunity in the HSV-2 mouse model. Int. Rev. Immunol. 22, 43-63 (2003).

88. Quispe Calla, N.E. et al. Medroxyprogesterone acetate and levonorgestrel increase genital mucosal permeability and enhance susceptibility to genital herpes simplex virus type 2 infection. Mucosal. Immunol. 9 , 1571-1583 (2016). 
89. Vicetti Miguel, R.D. et al. Dendritic cell activation and memory cell development are impaired among mice administered medroxyprogesterone acetate prior to mucosal herpes simplex virus type 1 infection. J. Immunol. 189, 3449-3461 (2012).

90. Kaushic, C., Ashkar, A.A., Reid, L.A. \& Rosenthal, K.L. Progesterone increases susceptibility and decreases immune responses to genital herpes infection. J. Virol. 77, 4558-4565 (2003).

91. Gillgrass, A.E., Fernandez, S.A., Rosenthal, K.L. \& Kaushic, C. Estradiol regulates susceptibility following primary exposure to genital herpes simplex virus type 2, while progesterone induces inflammation. J. Virol. 79, 3107-3116 (2005).

92. MacDonald, E.M. et al. Susceptibility of human female primary genital epithelial cells to herpes simplex virus, type-2 and the effect of TLR3 ligand and sex hormones on infection. Biol. Reprod. 77, 1049-1059 (2007).

93. Kaushic, C., Zhou, F., Murdin, A.D, \& Wira, C.R. Effects of estradiol and progesterone on susceptibility and early immune responses to Chlamydia trachomatis infection in the female reproductive tract. Infect. Immun. 68, 4207-4216 (2000).

94. Gursahaney, P.R., Meyn, L.A., Hillier, S.L., Sweet, R.L. \& Wiesenfeld, H.C. Combined hormonal contraception may be protective against Neisseria gonorrhoeae infection. Sex Transm. Dis. 37, 356-360 (2010).

95. Edwards, J.L. Neisseria gonorrhoeae survival during primary human cervical epithelial cell infection requires nitric oxide and is augmented by progesterone. Infect. Immun. 78, 1202-1213 (2010).

96. Xu, L. et al. Progesterone suppresses Th17 cell responses, and enhances the development of regulatory $T$ cells, through thymic stromal lymphopoietin-dependent mechanisms in experimental gonococcal genital tract infection. Microbes Infect. 15, 796-805 (2013).

97. Vodstrcil, L.A. et al. Hormonal contraception is associated with a reduced risk of bacterial vaginosis: a systematic review and meta-analysis. PLOS ONE. 8, e73055 (2013).

98. Alves, C.T., Silva, S., Pereira, L., Williams, D.W., Azeredo, J. \& Henriques, M. Effect of progesterone on Candida albicans vaginal pathogenicity. Int. J. Med. Microbiol. 304, 1011-1017 (2014).

99. Kita, E. et al. Alterations of host resistance to mouse typhoid infection by sex hormones. J. Leukoc. Biol. 46, 538-546 (1989).

100. Escobedo, G. et al. Progesterone induces mucosal immunity in a rodent model of human taeniosis by Taenia solium. Int. J. Biol. Sci. 7, 1443-1456 (2011).

101. Saqui-Salces, M., Rocha-Gutierrez, B.L., Barrios-Payan, J.A., Ruiz-Palacios, G., Camacho-Arroyo, I. \& Gamboa-Dominguez, A. Effects of estradiol and progesterone on gastric mucosal response to early
Helicobacter pylori infection in female gerbils. Helicobacter 11, 123-130 (2006).

102. Markle, J.G. et al. Sex differences in the gut microbiome drive hormone-dependent regulation of autoimmunity. Science 339, 1084-1088 (2013).

103. Vom Steeg, L.G. \& Klein, S.L. Sex steroids mediate bidirectional interactions between hosts and microbes. Horm. Behav. 88, 45-51 (2016).

104. Kleynhans, L. et al. The contraceptive depot medroxyprogesterone acetate impairs mycobacterial control and inhibits cytokine secretion in mice infected with Mycobacterium tuberculosis. Infect. Immun. 81, 1234-1244 (2013).

105. Boulet, S.L. et al. Contraceptive use among nonpregnant and postpartum women at risk for unintended pregnancy, and female high school students, in the context of Zika preparedness - United States, 2011-2013 and 2015. MMWR Morb. Mortal. Wkly. Rep. 65, 780-787 (2016).

106. Feinen, B., Jerse, A.E., Gaffen, S.L. \& Russell, M.W. Critical role of Th17 responses in a murine model of Neisseria gonorrhoeae genital infection. Mucosal Immunol. 3, 312-321 (2010).

107. Liang, J., Sun, L., Wang, Q. \& Hou, Y. Progesterone regulates mouse dendritic cells differentiation and maturation. Int. Immunopharmacol. 6, 830-838 (2006).

108. Tayel, S.S., Helmy, A.A., Ahmed, R., Esmat, G., Hamdi, N. \& Abdelaziz, A.I. Progesterone suppresses interferon signaling by repressing TLR-7 and MxA expression in peripheral blood mononuclear cells of patients infected with hepatitis C virus. Arch. Virol. 158, 1755-1764 (2013).

109. Hellings, P.W., Vandekerckhove, P., Claeys, R., Billen, J., Kasran, A. \& Ceuppens, J.L. Progesterone increases airway eosinophilia and hyperresponsiveness in a murine model of allergic asthma. Clin. Exp. Allergy. 33, 1457-1463 (2003).

110. Yates, M.A., Li, Y., Chlebeck, P., Proctor, T., Vandenbark, A.A. \& Offner, H. Progesterone treatment reduces disease severity and increases IL-10 in experimental autoimmune encephalomyelitis. J. Neuroimmunol. 220, 136-139 (2010).

111. Hughes, G.C., Clark, E.A. \& Wong, A.H. The intracellular progesterone receptor regulates $\mathrm{CD} 4+\mathrm{T}$ cells and $\mathrm{T}$ cell-dependent antibody responses. J. Leukoc. Biol. 93, 369-375 (2013).

112. Murphy, K., Irvin, S.C. \& Herold, B.C. Research gaps in defining the biological link between HIV risk and hormonal contraception. Am. J. Reprod. Immunol. 72, 228-235 (2014).

113. Munoz, L.D., Serramia, M.J., Fresno, M. \& Munoz-Fernandez, M.A. Progesterone inhibits HIV-1 replication in human trophoblast cells through inhibition of autocrine tumor necrosis factor secretion. J. Infect. Dis. 195, 1294-1302 (2007). 